\title{
Demographic data of 112 cases transported to the emergency medicine clinic
}

\author{
Mucahit Kapci $^{\mathrm{a}}$, Kenan Ahmet Turkdogan ${ }^{\mathrm{b}}$, Mehmet Yigit ${ }^{\mathrm{b}}$, Orhan Akpinar ${ }^{\mathrm{a}}$, Ali Dumana, Mustafa Celik ${ }^{\mathrm{c}}$, Nejat Huni ${ }^{\mathrm{d}}$, \\ Abdullah Hizirkilic ${ }^{a}$, Huseyin Durmuş ${ }^{d}$
}

${ }^{a}$ Department of Emergency Medicine, Isparta State Hospital, Isparta, Turkey

${ }^{b}$ Department of Emergency Medicine, Bezmialem Vakif University, Istanbul, Turkey

${ }^{c}$ Department of Pediatric Surgery, Isparta State Hospital, Isparta, Turkey

${ }^{d}$ Isparta 112 Emergency Call Center, Isparta, Turkey

\section{ARTICLE INFO}

ABSTRACT

\section{Article History \\ Received $\quad 01 / 04 / 2014$ \\ Accepted $\quad 11 / 06 / 2014$}

\section{* Correspondence to:}

Kenan Ahmet Turkdogan

Department of Emergency Medicine,

Bezmialem Vakif University,

Istanbul, Turkey

e-mail: drturkdogan@gmail.com

\section{Keywords:}

112 cases

Demographic data

Emergency medicine

Pre-hospital emergency health service
The coordination between pre-hospital emergency health service and emergency department is one of the major indicators of the quality of emergency services. This coordination heavily depends on the appropriate patient referrals made by 112 command and control centers. The aim of this study is to examine the collaboration and coordination between emergency departments and 112 Command and Control Center in such regions where there are more than one hospital. Computer-based medical records of the patients who were transported to Isparta State Hospital Emergency Medicine Clinic via 112 emergency call and rescue ambulances were retrospectively analyzed in this descriptive study. The number of patients transported to emergency department via 112 emergency ambulance service accounts for $5.73 \%$ of all patients (59616) referred to our emergency department in the same period. Among the consultations requested, while neurology department ranked first with a total of 316 consultations $(20.4 \%)$, consultation with department of ophthalmology was only $4(0.2 \%)$. In order to achieve a good coordination between hospitals and 112 Command and Control Center, the same form should be used in the period from hospital admission to the end of the treatment.

J.Exp.Clin. Med., 2014; 31:87-90

\section{Introduction}

Patients are transported to the emergency departments (ED) at all hours of the day. One of the most important considerations in patient transportation is that the hospital to which the patients are taken should be well equipped and sufficient for the patients because our primary objective is to improve the conditions without interrupting the treatment.

The use of ambulance service and the ratio of service utilization vary by the type of accident, age of individuals or severity of disease, time of arrival to health institutions and economic status and health insurance of the patients. Acute patients or seriously injured individuals are those who use ambulance service more frequently (Eagle et al., 1993; Clark et al., 1999; Victor et al., 1999; Chu et al., 2001; Kawakami et al., 2007).

The provision of ambulance services in developed and developing countries and utilization rates of ambulance service in communities vary by socioeconomic and cultural conditions (Kidak et al., 2009). Emergency ambulance services are provided 24 hours uninterruptedly under the management of command and control centers within province or territory scale (Langhelle et al., 2004; Black and Davies, 2005; Marozas et al., 2007; Roudsari et al., 2007).

Literature on the relationship between emergency services and 112 generally involves ED of tertiary hospitals. Therefore, data on current mechanism are needed to improve the quality of secondary emergency services which are frequently ignored. The aim of this study is to make contribution to the information database for further improvement of the coordination between ED of our hospital and 112 services.

\section{Materials and methods}

Computer-based medical records of the patients who were transported to Isparta State Hospital Emergency Department via 112 emergency call and rescue ambulances between 01 January 2013 and 30 June 2013 were retrospectively analyzed in this descriptive study. For data collection, computer-based recording systems of 112 Command and Control Center and 
our hospital were used. Because trauma-related diseases of children were examined in our emergency department, patients aged 0-17 years were classified as children, 18-64 as adults, 65-74 as early geriatric, 75-84 as mid-geriatric and those $\geq 85$ as geriatric. Patient arrival times were divided into one-hour periods. The diagnoses of the patients in the emergency department were classified according to the international diagnostic codes and organ system. Termination of patients in the emergency room was classified as discharged, hospitalized, referral to other hospitals and died.

All the data obtained from the study were recorded on a standard program called "Statistical Package for Social Sciences for Windows 15.0" and analyzed. Frequency distribution was used in the analysis.

\section{Results}

In our region, a total of 6403 calls to 112 Command and Control Center were answered in the first half of 2013. Of these calls, 709 were intervention at the scene, 373 were inter-hospital transportation and 4324 were transportation to the hospital. Of the patients transported to the hospitals, 3416 were taken to the emergency service of our hospital.

Of the 3416 patients transported to our emergency department via 112 emergency ambulance service, 1886 $(55.2 \%)$ were male and $1530(44.8 \%)$ were female. Patient's classification according to their diagnosis on admission is as follows; trauma (1212), cardiovascular disease (434), psychiatric illness (420), neurological disease (389), respiratory system diseases (219), poisoning (186), gastrointestinal disease (154), infectious disease (123), metabolic and endocrine disorders (97), urinary system diseases (64), other diseases (75) and disease associated with obstetric and gynecology (43). The number of patients transported to emergency department via 112 emergency ambulance service accounts for $5.73 \%$ of 59616 patients who referred to our emergency department in the same period. The mean age of the patients was $47.82 \pm 7.24$. The distribution of the patients with respect to the age groups is summarized in Figure 1.

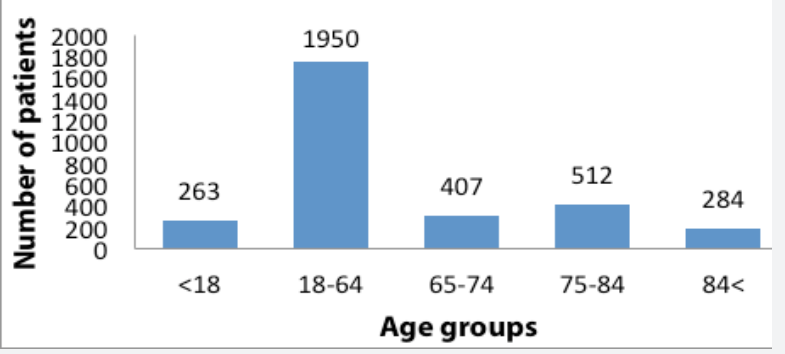

Fig. 1. Figure showing the distribution of patients with respect to the age groups

The distribution of the patients who were transported to the emergency department via 112 ambulances with respect to days of the week revealed that Friday ranked in the first place with $526(15.4 \%)$ patients and Sunday ranked last with $461(13.5 \%)$ patients. The distribution of the patients with respect to the hospital arrival times revealed that the most intense hours were the third and fourth quarters of the day.

Consultation with various departments was requested for 1220 patients and a total of 1548 consultation were done. Eight hundred and twenty-eight patients consulted were hospitalized in our hospital (Fig. 2). Nine hundred eighty-three (33.6\%) patients had one, $180(6.2 \%)$ two, 30 $(1.0 \%)$ three, $21(0.7 \%)$ four, $4(0.1 \%)$ five and $2(\% 0.1)$ six consultations.

Among the consultations requested, while neurology department ranked first with a total of 316 consultations (20.4\%), consultation with the department of ophthalmology

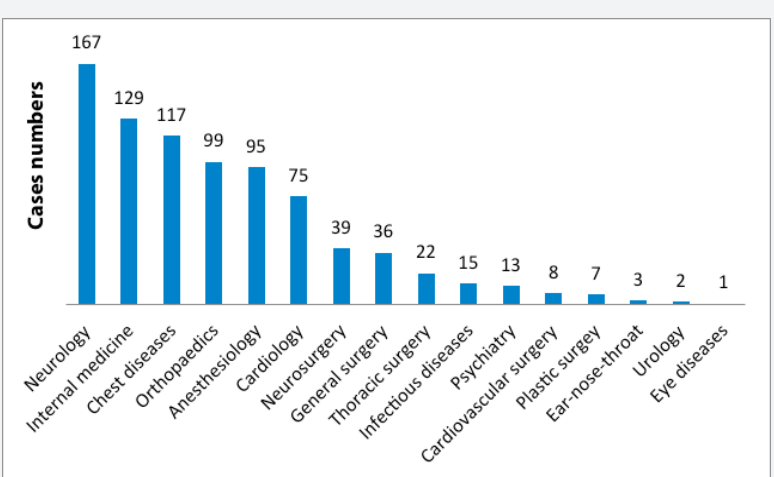

Fig. 2. Figure showing the distribution of patients with respect to the services

was only 4 (0.2\%) (Fig. 3). Consultation was requested for 316 of 389 patients with neurological symptoms and signs and 167 of these patients were hospitalized in the neurology department (Fig. 4).

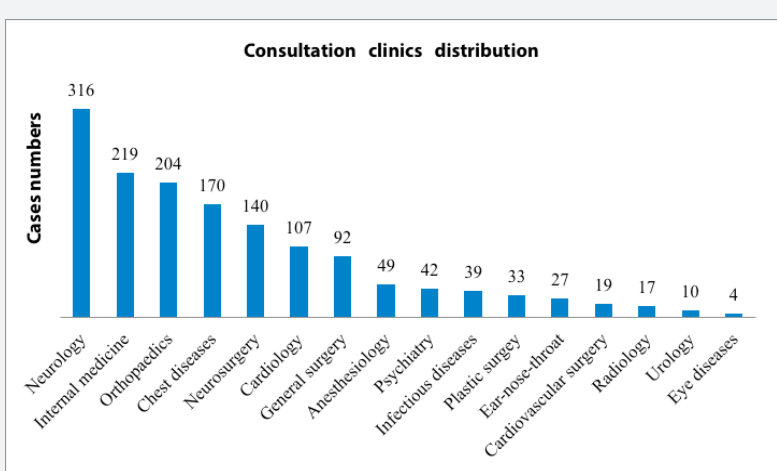

Fig. 3. Consultation clinics distribution

Of the patients taken to emergency services via 112 emergency service ambulances, 2505 were discharged from the hospital after completing the necessary diagnosis, treatment and follow-up procedures, 828 were hospitalized and 76 were referred to other hospitals due to reasons such as further examination or lack of empty bed. Seven patients died (Fig. 4). Distribution of the patient's diagnosis in the emergency department with respect to diagnosis group revealed that 1029 patients had trauma-related diagnosis codes.

\section{Discussion}

The number of ambulance and 112 stations in time. The demand for ambulance service has increased as well. Study conducted by Kidak et al. (2009) showed that the patients 


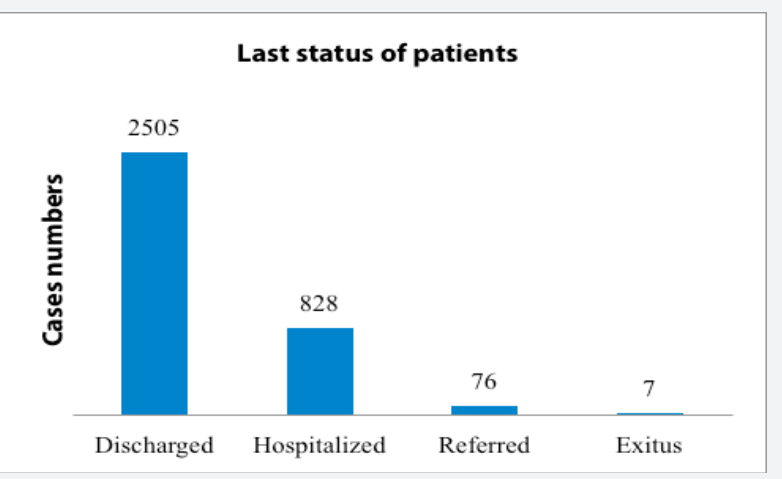

Fig. 4. Figure showing patients' outcomes in the emergency department

aged 65 or over account for $26.7 \%$ of all hospital admission in 2004 and 2005. It was reported in a study conducted in the United States that $36.4 \%$ of elderly patients were taken to the emergency departments by ambulance (Burt et al., 2006). The ratio of elderly patients transported to emergency service by ambulance varies between $20 \%$ and $55 \%$ among those admitted to emergency service (Downing and Wilson, 2005; Melby and Ryan, 2005). In our study, this ratio was $35.2 \%$. Studies showed that elderly patients use emergency ambulance services more frequently than other age groups. In comparison with other age groups, admission to emergency service was more common in patients aged 65 and over due to the health problems which increase with age (Akpinar et al., 2013). It was also determined in Kidak et al.'s study (2009) that emergency calls were mostly made in the evening and the number of calls decreased after midnight. Similar findings were obtained in several publications in the literature (Ali et al., 2006; Dundar et al., 2006). In our study, emergency calls were more frequent between the hours of 18:00 and 22:00. This is because the patients are able to find a companion only after work.

In the study of Olia et al. (2002) which conducted in Italy, they reported that $17 \%$ of all ambulance calls were due to trauma. It was reported in a study that trauma cases constitutes $41 \%$ of all emergency patient transports in Norway in 2001 (Langhelle et al., 2004). Despite regional variations, the rate of hospital referral due to trauma which ranges from 17 to $41 \%$ was found to be $30.12 \%$ in our study (1029 patients).

According to the data of Ministry of Health General Directorate of Primary Health Care Yearbook (2006), trauma (25.7\%) and cardiovascular system diseases (19.5\%) were most frequent among all emergency pre-diagnoses in Turkey. Again, in the same yearbook, trauma (24.3\%), cardiovascular system diseases $(20.6 \%)$ and neurological disease $(10.7 \%)$ were most frequent among all emergency pre-diagnoses in Izmir, a province in Aegean Region (T.C. Ministry of Health General Directorate of Primary Health Care, 2007). In a study which involves various age groups in Sweden, cardiac causes (12\%) were most frequent among all emergency cases (Hjalte et al., 2007). In a study conducted in Norway, trauma (41\%) and cardiac problems (27\%) were found to be most frequent reasons for emergency referrals (Langhelle et al., 2004). In a similar study conducted in Italy, respiratory distress (16.7\%), loss of consciousness $(16.6 \%)$ and chest pain $(11.8 \%)$ were found to be most frequent reasons among all emergency calls (Olia et al., 2002). Consistent with the literature, trauma $(35.48 \%)$ and cardiovascular disease $(12.70 \%)$ took the first and second places in our study respectively.

Diagnoses made by the ambulance crew are not based on any international classification, rather signs and symptoms are considered. There is no a common classification system in our study. The rate of intervention at scene is $11 \%$ in our study and this ratio varies across the different studies. In our study, of the stations, this rate varies according to whether the doctor.

According to the report of Ministry of Health General Directorate of Primary Health Care Yearbook (2006) of Turkey, $3.9 \%$ percent of patients who called ambulance services were transported by other vehicles, $2.4 \%$ were dead, $0.7 \%$ were false alarm and ambulance run cancellation rate was $2.8 \%$ (T.C. Ministry of Health General Directorate of Primary Health Care, 2007). It was determined in Kidak et al's study (2009) that $1.3 \%$ of the cases refused being transported by ambulance and $5.6 \%$ were found dead when the ambulance arrived on science. In our study, the rate of those who refused being transported by ambulance was 12.55 $\%$ and death rate was $1.93 \%$.

Three hundred and seventy three inter-hospital transports in our study were the cases that were referred to another hospital for further examination due to lack of necessary examination and treatment or those who were referred to our hospital. Referrals occur because of the fact that some services such as angio unit, closed psychiatric service and hematology unit are not available in our hospital.

In conclusion; 112 command and control center directing cases to hospitals should provide detailed information about the patients to the hospital. We must use the same form to be consistent the records with 112 command and control center in hospital. 112 command control center must be informed that the hospital equipment and choice of hospital must be provided relief to them. So that patients will be redirected to hospitals which have essential equipment and specialist physicians and time loss will be prevented.

\section{REFERENCES}

Akpınar, O., Turkdogan, K.A., Sen, M., Duman, A., Karabacak, M., 2013. Infection diseases in geriatric patients who admitted to emergency department. J Clin Anal Med. 6, 1-4. doi: 10.4328/JCAM.

Ali, M., Miyoshi, C., Ushijima, H., 2006. Emergency medical services in Islamabad, Pakistan: A public-private partnership. Public Health 120, 50-57.

Black, J.M., Davies, G.D., 2005. International EMS Systems: United Kingdom. Resuscitation. 64, 21-29.

Burt, C.W., McCalg, L.F., Valverde, R.H., 2006. Analysis of ambulance transports and diversions among US emergency departments. Ann. Emerg. Med. 47, 317-326.

Chu, K., Brown, A., Pillay, R., 2001. Older patient's utilisation of emergency department resources: A cross-sectional study. Aust. Health Rev. 24, 44-52.

Clark, M.J., Purdie, J., Fitz Gerald, G.J., Bischoff, N.G., O’Rourke, P.K., 1999. Predictors of demand for emergency prehospital care: An Australian study. Prehospital Disaster Med. 14, 167-173. 
Downing, A., Wilson, R., 2005. Older people's use of accident and emergency services. Age Ageing 34, 24-30.

Dundar, C., Sunter, A.T., Canbaz, S., Cetinoglu, E., 2006. Emergency service use by older people in Samsun, Turkey. Adv. Therapy. 23 , 47-53.

Eagle, J., Rideout, E., Price, M., McMann, C., Wonnacot, E.,1993. Misuse of emergency department by elderly population: Myth or realty. J. Emerg. Nurs. 19, 212-218.

Hjalte, L., Suserud, B.O., Herlitz, J., Kalberg, I., 2007. Why are people without medical needs transported by ambulance? A study of indications for pre-hospital care. Eur. J. Emerg. Med. 14, 151-156.

Kawakami, C., Ohshige, K., Kubota, K., Tochikubo, O., 2007. Influence of socioeconomic factors on medically unnecessary ambulance calls. BMC Health Serv. Res. 7, 120-129.

Kidak, L., Keskinoglu, P., Sofuoglu, T., Olmezoglu, Z., 2009. The evaluation of 112 emergency ambulance service uses in Izmir. Genel Tip Derg. 19, 113-119.

Langhelle, A., Lossius, H.M., Silfvast, T., Björnsson, H.M., Lippert, F.K., Ersson, A., Soreide, E., 2004. International EMS systems: The Nordic countries. Resuscitation 61, 9-21.

Marozas, R., Rimdeika, R., Jasinskas, N., Vaitkaitiene, E., Vaitkaitis, D., 2007. The ability of Lithuanian ambulance services to provide first medical aid in trauma cases. Medicina (Kaunas). 43, 463-471.

Melby, V., Ryan, A, 2005. Caring for older people in prehospital emergency care: Can nurses make a difference? J. Clin. Nurse. 14,1141-1150.

Olia, P.M., Mollica, T.V., Querci, A., 2002. Eight months of emergency services by ambulance (with doctor on board) of the Emergency Department of Prato, Italy. Minerva Anestesiol. 68, 849-854.

Roudsari, B.S., Nathens, A.B., Arreola-Risa, C., Cameron, P., Civil, I., Grigoriou, G., Gruen, R.L., Koepsell, T.D., Lecky, F.E., Lefering, R.L., Liberman, M., Mock, C.N., Oestern, H.J., Petridou, E., Schildhauer, T.A., Waydhas, C., Zargar, M., Rivara, F.P., 2007. Emergency Medical Service (EMS) systems in developed and developing countries. Injury. 38, 1001-1013.

T. C. Ministry of Health General Directorate of Primary Health Care, 2007. Temel sağlık hizmetleri genel müdürlüğü çalışma yıllığı 2006. 1. bask1, Ankara, Kuban Matbaacilık Yayınc1lık, pp.137-145.

Victor, C.R., Peacock, J.L., Chazot, C., Walsh, S., Holmes, D., 1999. Who calls 999 an why? A survey of the emergency workload of the London Amulance Service. J. Accid. Emerg. Med. 16, 174-178. 